\title{
Development and Sensitivity of a 12-h Laboratory Test with Daphnia magna Straus Based on Avoidance of Pulp Mill Effluents
}

\author{
R. Rosa · M. Moreira-Santos $\cdot$ I. Lopes $\cdot$ A. Picado $\cdot$ \\ E. Mendonça $\cdot$ R. Ribeiro
}

Received: 14 February 2008/Accepted: 22 August 2008/Published online: 9 September 2008

(C) Springer Science+Business Media, LLC 2008

\begin{abstract}
Studies on avoidance of contaminants by aquatic organisms verified that such behavior may have crucial ecological implications. Yet, avoidance tests have not been considered in ecological risk assessments. This study aimed at developing a short-term test with Daphnia magna Straus based on avoidance of pulp mill effluents and at comparing its sensitivity to the standard $21 \mathrm{~d}$ D. magna reproduction test. The avoidance effective dilution values (12 h EDil20 and EDil50) were as sensitive as the $21 \mathrm{~d}$ EDil20 and EDil50 values for reproduction. Therefore, this easily standardizable short-term test can be recommended as a valuable complementary tool in ecological risk assessments.
\end{abstract}

Keywords Test development - Short-term test .

Behavior · Paper industry

The avoidance of contaminants by aquatic organisms is an example of a measurable behavioral response that can be used in risk assessment studies to more accurately assess ecosystem quality (Little et al. 1993; Scott and Sloman

R. Rosa $\cdot$ M. Moreira-Santos $(\bowtie) \cdot$ R. Ribeiro

IMAR-Instituto do Mar, Department of Zoology,

University of Coimbra, Largo Marquês de Pombal,

3004-517 Coimbra, Portugal

e-mail: matilde.santos@zoo.uc.pt

I. Lopes

CESAM (Centro de Estudos do Ambiente e do Mar)

\& Departamento de Biologia, Universidade de Aveiro,

Campus de Santiago, 3810-193 Aveiro, Portugal

A. Picado - E. Mendonça

Instituto Nacional de Engenharia, Tecnologia e Inovação,

Estrada do Paço do Lumiar, 1649-038 Lisbon, Portugal
2004; Riddell et al. 2005). Several studies have demonstrated avoidance of contaminants by aquatic organisms, namely cladocerans (Lopes et al. 2004), amphipods (Kravitz et al. 1999; De Lange et al. 2006), chironomid larvae (Wentsel et al. 1977), and fish (Åtland and Barlaup 1995; Svecevičius 2001; Wells et al. 2004; Moreira-Santos et al. 2008). Although avoidance responses may have important ecological implications, even at the ecosystem level (Little et al. 1993; Lopes et al. 2004), and occur at levels of contamination below those causing lethal and sublethal effects (Little et al. 1993; Wells et al. 2004; Lopes et al. 2004), avoidance-based aquatic tests have not been included in risk assessment studies. Furthermore, almost all ecotoxicological tests that have been proposed involve the exposure of the test organisms in a confined system, i.e., their forced exposure to the toxicants. The extrapolation from responses in such tests may underestimate adverse effects under real contamination scenarios, since natural populations may often evade from polluted areas. Hansen et al. (1999) demonstrated that differences in the avoidance responses of two trout species in a metal-impacted river may partially explain the abundance and distribution of these two species. Also, West and Ankley (1998) observed that the oligochaeta Lumbriculus variegatus Müller avoided field-collected contaminated sediments with slight or no toxicity in standard growth and/or survival tests. Therefore, avoidance-based tests should be considered as complementary tools within ecological risk assessment.

The main aim of this study was to develop a short-term (12 h) test with the standard cladoceran species Daphnia magna Straus based on avoidance as a complementary tool to improve ecological realism in the risk assessment of pulp mill effluents. To evaluate the potential of the proposed assay for routine toxicity assessments, its sensitivity was compared to that of the standard 21 d D. magna 
reproduction test. Pulp mill effluents are considered pollutants of high environmental concern to aquatic organisms due to the high volumes produced and the presence of a large number of potentially toxic compounds, mainly wood extractives, chlorinated and sulphur compounds (Ali and Sreekrishnan 2001). Avoidance tests were performed with four different samples of an elemental chlorine-free (ECF) bleached-kraft pulp mill effluent from the blue gum $E u$ caliptus globulus Labill. Daphnia magna was selected as the test organism because it is a key species in aquatic ecotoxicology. Daphnia plays an important role in the food webs of a wide range of freshwater habitats. Daphnia magna, in particular, is easily cultured in the laboratory and has been extensively used in standard toxicity testing (e.g. OECD 1998a, 2004; ASTM 2001), often mandatory for regulatory purposes (e.g. EC 1992).

\section{Materials and Methods}

All D. magna used in tests were third to fifth brood neonates (6-24 h old) obtained from laboratory cultures maintained at $20-22^{\circ} \mathrm{C}$ under a $14 \mathrm{~h}: 10 \mathrm{~h}$ light:dark photoperiod. Culture medium was a reconstituted ASTM hard water (ASTM 2002) supplemented with vitamins $(7.5 \mu \mathrm{g} / \mathrm{L}$ of $\mathrm{B}_{1}, 1 \mu \mathrm{g} / \mathrm{L}$ of $\mathrm{B}_{12}$ and $0.75 \mu \mathrm{g} / \mathrm{L}$ of biotin) and Marinure extract (Glenside, Stirling, UK) $(7.5 \mathrm{~mL} / \mathrm{L}$ of a suspension with an absorbance of 620 units at $400 \mathrm{~nm}$ ), and was renewed every other day. Cultures ( 25 and 12 daphnids/L up to the first brood and from there onwards, respectively) were fed daily with Pseudokirchneriella subcapitata (Koršhikov) $\left(3 \times 10^{5}\right.$ cells $\left./ \mathrm{mL}\right)$.

The avoidance tests were conducted in the flow-through system used by Moreira-Santos et al. (2008) for avoidance tests with Danio rerio Hamilton and composed of three replicated five-compartment chambers (without Teflon rings in-between compartments), three solution (100\%, $50 \%$ and $0 \%$ of toxicant) and a waste reservoir, and two peristaltic pumps.

Prior to all tests, a $12 \mathrm{~h}$ calibration of the test system to obtain a stable and linear gradient of contamination and a good among-chambers replicability was performed in the absence of organisms following Moreira-Santos et al. (2008) procedures, but using a solution of sodium chloride ( NaCl; Merck, Darmstadt, Germany) dissolved in ASTM water $(0.1 \mathrm{~g} / \mathrm{L})$, whose concentration was measured indirectly by conductivity (WTW LF 92 conductivity meter, Wissenschaftlich Technische Werkstätten, Weilheim, Germany) ( $\left.r^{2}=99.9 \%, p<10^{-9}, \mathrm{n}=7\right)$. The calibration followed three steps: (1) $100 \%, 50 \%$ and $0 \%$ of the $0.1 \mathrm{~g} / \mathrm{L}$ $\mathrm{NaCl}$ solution were delivered to each replicate chamber; (2) compartments were isolated with plasticine spheres and the five compartments of each chamber filled with $300 \mathrm{~mL}$ of the expected gradient of $90 \%, 70 \%, 50 \%, 30 \%$, and $10 \%$ of the $0.1 \mathrm{~g} / \mathrm{L} \mathrm{NaCl}$ solution; (3) the plasticine spheres were removed and the flow-through system immediately started up. Measurements of conductivity were taken $2 \mathrm{~h}$ later, to obtain a near equilibrium situation, and again after a $12 \mathrm{~h}$ calibration period.

To verify whether $D$. magna distribution was influenced by experimental factors other than the presence of the toxicant, a test was carried out solely with ASTM water following the calibration procedures. The test was initiated by introducing 10 neonates in the middle of each compartment and was conducted for $12 \mathrm{~h}$ in darkness. At the end of the $12 \mathrm{~h}$ test period, the connections between the chamber compartments were closed with the plasticine spheres and the number of organisms present in each compartment was counted.

Avoidance tests were performed with four different samples from an ECF bleached-kraft pulp mill effluent (A, $\mathrm{B}, \mathrm{C}$, and $\mathrm{D}$ ), according to the procedures described above. Samples A, B and C were collected at different times prior to the implementation of secondary treatment in the mill, and sample D after that. All effluent dilutions were prepared with ASTM water. Preliminary trials exposing D. magna neonates ( $24 \mathrm{~h}$ old) to $100 \%$ and $80 \%$ of effluent during a $48 \mathrm{~h}$ period revealed $90 \%$ and $40 \%$ mortality, respectively, for sample $\mathrm{A}$, whereas $100 \%$ survival was observed in samples B, C and D. Thus, to ensure no lethal effects during testing, D. magna was exposed to a gradient of $32 \%, 25 \%, 18 \%, 11 \%$, and $4 \%$ for sample A, whereas for the remaining three samples a gradient of $90 \%, 70 \%$, $50 \%, 30 \%$, and $10 \%$ was tested (the three reservoirs were filled with $35 \%, 18 \%$ and $0 \%$ of sample A and $100 \%, 50 \%$ and $0 \%$ of samples $\mathrm{B}, \mathrm{C}$ and $\mathrm{D}$ ). The range of $\mathrm{pH}$ (WTW $537 \mathrm{pH}$ meter) and conductivity values measured at the beginning of each test are presented in Table 1.

The results of the $12 \mathrm{~h}$ avoidance tests were compared to the results of $21 \mathrm{~d}$ reproduction tests conducted with samples A and C in the present study and with samples B and $\mathrm{D}$ in a previous study (unpublished data). The samples were subjected to the following dilution gradients: $15 \%$, $19 \%, 24 \%, 30 \%$ and $38 \%$ of sample A; $25 \%, 34 \%, 46 \%$, $62 \%$, and $83 \%$ of samples B and C; and $34 \%, 46 \%, 62 \%$, $83 \%$, and $100 \%$ of sample $\mathrm{D}$, as the latter was collected after the implementation of secondary treatment in the mill and thus expected to be less toxic (Hewitt et al. 2006). The reproduction tests were carried out according to OECD (1998a) guidelines. The ASTM water was used as control and dilution medium. Ten replicates were set up for each treatment, each with $50 \mathrm{~mL}$ of test solution and one organism. During testing, the feeding regime, medium renewal frequency and incubation conditions were similar to those used for culturing. After the $21 \mathrm{~d}$ exposure period, fecundity was determined as the total number of neonates 
Table 1 Range of $\mathrm{pH}$, conductivity (cond., in $\mu \mathrm{S} / \mathrm{cm}$ ) and dissolved oxygen (DO, in $\mathrm{mg} / \mathrm{L}$ ) measurements, from the lowest to the highest effluent percentage, measured during the $12 \mathrm{~h}$ avoidance and $21 \mathrm{~d}$ reproduction tests performed with four different samples (A, B, C, and D) of an elemental chlorine-free bleached-kraft pulp mill effluent

\begin{tabular}{llcccc}
\hline Test & Parameter & Effluent sample & & \\
\cline { 3 - 6 } & & $\mathrm{A}$ & $\mathrm{B}$ & $\mathrm{C}$ & $\mathrm{D}$ \\
\hline Avoidance & $\mathrm{pH}$ & $7.7-7.4$ & $7.9-7.0$ & $7.6-6.8$ & $830-2,880$ \\
& Cond. & $700-1,640$ & $920-3,730$ & $7.7-7.3$ & $7.3-3,710$ \\
Reproduction & $\mathrm{pH}$ & $7.6-7.9$ & $7.2-7.1$ & $1,190-2,570$ & $1,670-3,720$ \\
& Cond. & $1,010-1,760$ & $1,392-3,370$ & $9.2-8.2$ & $8.5-11$ \\
\hline
\end{tabular}

released per female. Table 1 presents the range of $\mathrm{pH}$, conductivity and dissolved oxygen (WTW OXI 92 oxygen meter) values measured in three replicate test solutions of new and old medium, at all renewal days.

The replicability of the $\mathrm{NaCl}$ gradient among the three replicate chambers was tested by comparing the slopes and elevations of the three regression lines of $\mathrm{NaCl}$ dilutions against conductivity, at the start and also at the end of the $12 \mathrm{~h}$ calibration. Chi-square goodness of fit tests were used to evaluate both the stability of the $\mathrm{NaCl}$ gradient, by comparing the mean conductivity values $(n=3)$ in the compartments at the start and end of the $12 \mathrm{~h}$ calibration, and the linearity of the $\mathrm{NaCl}$ gradient, by comparing the observed (mean values; $\mathrm{n}=3$ ) and expected dilution gradient of $90 \%, 70 \%, 50 \%, 30 \%$, and 10\%. One-tailed Fisher's exact tests were used to compare the observed and expected distribution of D. magna. In case avoidance was observed, both the number of avoiders and the avoidance percentage per compartment were computed. The number of avoiders (A) was calculated by:

$A_{i}=\sum_{c=1}^{c=i} E_{c}+\sum_{c=1}^{c=i} O_{c}$

where $i$ is the compartment number, varying from 1 to 5 (decreasing percentage of toxicant, $c=1$ being the compartment with the highest concentration of effluent), $E_{c}$ is the number of organisms expected in compartment $c$ and $O_{c}$ is the number of organisms observed in compartment $c$. The avoidance percentage was calculated as the ratio between the number of missing (avoiders) and expected organisms. The effective dilutions inducing 20\% (EDil20) and $50 \%$ (EDil50) of avoidance and respective $95 \%$ confidence limits (CL) were computed using the software PriProbit 1.63 (http://bru.gmprc.ksu.edu/proj/priprobit/ download.asp), with the probit transformation of the proportion of avoiders and the $\log$ transformation of the dilution values. Regarding the reproduction tests, one-way analysis of variance followed by Dunnett's tests, when applicable, were performed to test for significant differences between the control and the effluent dilutions and obtain the no-observed-effect concentration (NOEC) and lowest-observed-effect concentration (LOEC) values. The EDil20 and EDil50 values and respective 95\% CL were calculated by fitting organism responses to a logistic model (OECD 1998b).

\section{Results and Discussion}

Regarding the calibration of the test system, there were no significant differences in the $\mathrm{NaCl}$ gradients among the three replicate test chambers either at the start (slopes: $F_{2,9}=0.323, \quad p>0.05$; elevations: $\quad F_{2,11}=0.347$, $p>0.05$ ) or at the end (slopes: $F_{2,9}=0.298, p>0.05$; elevations: $\left.F_{2,11}=0.466, p>0.05\right)$ of the $12 \mathrm{~h}$ calibration. Also, significant differences were found neither between the values of conductivity measured in each compartment at the start and end of calibration $\left(\chi_{4}^{2}=1.74\right.$, $p=0.78$ ) nor between the observed and expected $\mathrm{NaCl}$ dilutions values of $90 \%, 70 \%, 50 \%, 30 \%$ and $10 \%$ $\left(\chi_{4}^{2}=5.46, p=0.24\right)$. When exposed solely in ASTM medium for $12 \mathrm{~h}$, the number of organisms observed in the extreme compartments of the chambers did not significantly differ from that observed at the start of the test (expected uniform distribution) $(p>0.05)$. This good among-chambers replicability and overall stability and linearity of the gradient of contamination that was established during the $12 \mathrm{~h}$ test period $(90 \%, 70 \%, 50 \%, 30 \%$ and $10 \%$ ) corroborated the results obtained by MoreiraSantos et al. (2008) and Dornfeld et al. (2008) when developing a test system for conducting avoidance tests with small fish and the macroinvertebrate Chironomus riparius Meigen, respectively. The present results confirmed, thus, the suitability of the test system to more realistically simulate a gradient of contamination that often occurs under natural conditions. Conversely, many of the proposed avoidance tests expose the organisms to an abrupt toxicant gradient (Hansen et al. 1999; Kravitz et al. 1999) that only occurs sporadically when contaminants enter water bodies in form of a plume. Furthermore, the present 
Table 2 Mean $(n=3)$ percentage of avoidance in the three test chamber compartments with the highest percentages of four different samples (A, B, C, and D) of an elemental chlorine-free bleached-kraft pulp mill effluent by Daphnia magna neonates exposed for $12 \mathrm{~h}$

\begin{tabular}{|c|c|c|c|c|c|c|}
\hline \multirow{2}{*}{$\begin{array}{l}\text { Effluent } \\
\text { sample }\end{array}$} & \multicolumn{6}{|c|}{ Dilutions (\%) } \\
\hline & 90 & 70 & 50 & 32 & 25 & 18 \\
\hline A & nt & $\mathrm{nt}$ & $\mathrm{nt}$ & $100 *$ & $90^{*}$ & $56 *$ \\
\hline B & $93 *$ & $83 *$ & $73 *$ & $\mathrm{nt}$ & $\mathrm{nt}$ & $\mathrm{nt}$ \\
\hline C & $93 *$ & $95^{*}$ & $73 *$ & $\mathrm{nt}$ & $\mathrm{nt}$ & $\mathrm{nt}$ \\
\hline D & $20 *$ & 7 & 4 & $\mathrm{nt}$ & $\mathrm{nt}$ & nt \\
\hline
\end{tabular}

* Significant avoidance by one-tailed Fisher's exact test $\mathrm{nt}=$ not tested

results demonstrated that D. magna did not avoid any of the extremities of the test chambers in the absence of a toxicant gradient, and, thus, the suitability of the system to determine whether D. magna avoids toxic substances.

The results of the avoidance tests presented in Table 2 show that $D$. magna significantly avoided the three highest effluent percentages of samples A, B and C $(p<0.001)$, whereas for sample D only the highest effluent percentage was avoided $(p=0.012)$. In addition, the percentage of avoiders increased with the rise in the effluent percentage. These results indicate that $D$. magna was sensitive to the effluent gradient and was able to avoid the highest percentages to escape the detrimental effects posed by this pulp mill effluent. Besides, they show that the intensity of the response was associated with the percentage of the effluent. The present results are in agreement with those obtained by Lopes et al. (2004) demonstrating that the strength of the avoidance response of D. longispina to copper was strongly associated with the copper concentration. Also, Wiklund et al. (2006) observed that the avoidance response of the amphipod Monoporeia affinis Lindstrom was related to the concentration of zinc pyrithione in the sediment. Information on the avoidance responses of aquatic organisms to pulp mill effluents dates from the 1960s and 1970s, is scarce, is practically restricted to studies with fish, though avoidance has been reported for lobsters and snails, and both avoidance and preference behavioral responses have been observed (reviewed in Hutchins 1979 and CEPA 1991). Moreover, these studies could not identify the effluent compounds or fractions $(\mathrm{pH}$ dissolved oxygen, turbidity, biological oxygen demand, adsorbable organic halogens) potentially responsible for the observed effects (Hutchins 1979; CEPA 1991).

Results of the reproduction tests illustrated in Fig. 1 show that $D$. magna fecundity was significantly inhibited by all dilutions of effluent sample $\mathrm{A}\left(F_{5,52}=66.9\right.$, $p<0.001)$ and for an effluent percentage higher than or equal to $46 \%$ for samples $\mathrm{B}\left(F_{5,53}=92.6, p<0.001\right)$ and

Table 3 No-observed-effect concentration (NOEC) and lowestobserved-effect concentration (LOEC) values of the $21 \mathrm{~d}$ reproduction tests exposing Daphnia magna neonates to four different samples (A, $\mathrm{B}, \mathrm{C}$, and D) of an elemental chlorine-free bleached-kraft pulp mill effluent

\begin{tabular}{lll}
\hline Effluent sample & NOEC $(\%)$ & LOEC $(\%)$ \\
\hline A & $<15$ & 15 \\
B & 46 & 62 \\
C & 46 & 62 \\
D & No effect & No effect \\
\hline
\end{tabular}

Fig. 1 Mean $(\mathrm{n}=10)$ reproductive output of Daphnia magna (number of neonates) during $21 \mathrm{~d}$ reproduction tests with four different samples (A, B, C, and D) of an elemental chlorine-free bleached-kraft pulp mill effluent. Error bars indicate \pm 1 standard deviation; asterisks above error bars indicate significant fecundity inhibition relatively to control by Dunnett's test (following oneway ANOVA)
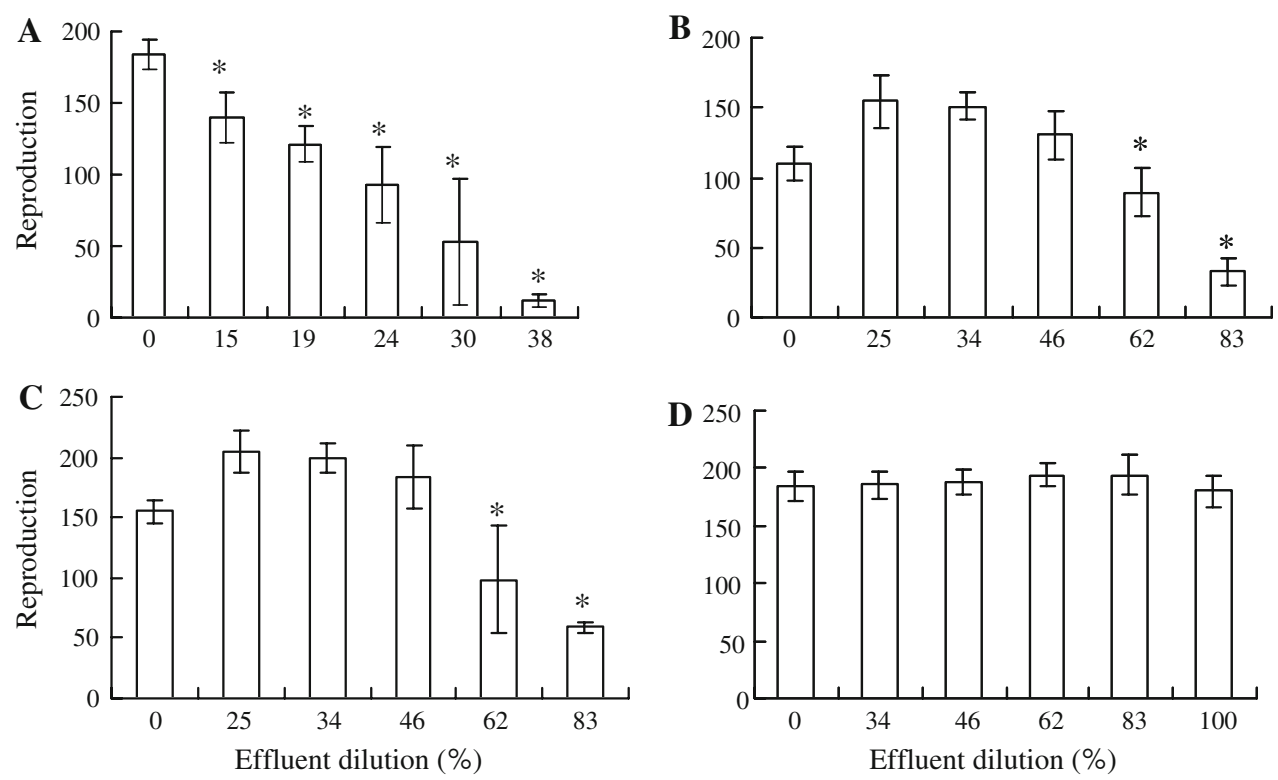
Table 4 Median $12 \mathrm{~h}$ avoidance and $21 \mathrm{~d}$ reproductive effective dilutions inducing 20\% and 50\% responses (EDil20 and EDil50) and respective 95\% confidence limits (in brackets) for Daphnia magna neonates exposed to four different samples (A, B, C, and D) of an elemental chlorinefree bleached-kraft pulp mill effluent

\begin{tabular}{|c|c|c|c|c|}
\hline \multirow{2}{*}{$\begin{array}{l}\text { Effluent } \\
\text { sample }\end{array}$} & \multicolumn{2}{|l|}{ Avoidance } & \multicolumn{2}{|l|}{ Reproduction } \\
\hline & EDil20 (\%) & EDil50 (\%) & EDil20 (\%) & EDil50 (\%) \\
\hline A & $9.80(8.60-10.8)$ & $14.5(13.5-15.7)$ & $15.8(13.4-17.9)$ & $21.5(19.9-23.0)$ \\
\hline B & $28.0(24.8-30.8)$ & $40.4(37.5-43.4)$ & $40.7(35.5-45.9)$ & $55.3(50.9-59.7)$ \\
\hline $\mathrm{C}$ & $21.0(8.48-29.1)$ & $33.5(21.9-46.1)$ & $38.9(32.1-45.8)$ & $54.4(48.4-60.4)$ \\
\hline D & $100(78.4-204)$ & No effect & No effect & No effect \\
\hline
\end{tabular}

C $\left(F_{5,53}=62.2, p<0.001\right)$. No significant effects on reproduction were found for effluent sample D $\left(F_{5,54}=1.89, p=0.11\right)$. In accordance with the avoidance responses, the reproduction results presented in Table 3 clearly indicate that effluent sample A was the one presenting the highest toxicity, with a LOEC as low as $15 \%$ of effluent, followed by samples $\mathrm{B}$ and $\mathrm{C}$ with a LOEC value of $62 \%$ of effluent. In effect, Table 4 reveals that the avoidance and reproduction tests provided a similar pattern of responses for the four effluent samples, i.e., a similar ranking of sample toxicity. Effluent sample A was the most toxic followed equally by samples B and C, whereas sample $\mathrm{D}$ did not cause toxicity either on the avoidance or reproduction of D. magna. As sample A was collected at the time the mill was in the process of introducing secondary treatment, its high toxicity may be associated to some malfunction during the effluent treatment procedures. Samples B and C were both collected when only primary treatment was applied to the effluent, whereas sample D was collected after the implementation of secondary treatment. Therefore, differences in toxicity among the effluent samples were very likely associated to the different levels of effluent treatment. In fact, secondary treatment is effective in reducing effluent toxicity by reducing the effluent levels of legislated parameters (EC 2001), like chemical oxygen demand, biological oxygen demand, adsorbable organic halogens, and total suspended solids, and also of certain toxic compounds (e.g. wood extractives) (Hewitt et al. 2006; Parrott et al. 2006). Table 4 also shows that the ratios between the EDil20 values for reproduction and avoidance and between the correspondent EDil50 values ranged between 1.4 and 1.9, even though the 95\% CL of the EDil20 and EDil50 values for avoidance and reproduction never overlapped. The fact that these ratios were below a twofold factor, and, thus, within the variability generally acceptable in toxicity tests (Chapman 2000), reveals that the sensitivity of the avoidance and reproduction responses was similar. However, because the $95 \%$ confidence limits of the EDil values for avoidance and reproduction never overlapped, it appears that the avoidance responses may occur at lower concentrations than those affecting reproduction.
Habitat avoidance may alter the structure of the communities in the receiving waters, either directly by emigration or indirectly through alterations in food resources (Lopes et al. 2004; De Lange et al. 2006). Daphnia spp., in particular, are important components of the zooplankton being key elements of the food chain. As a result, alterations in their population dynamics will probably have important ecological implications at population and community levels. The results of the present study showed that the effects of the ECF bleached-kraft pulp mill effluent on the reproduction of $D$. magna did not provide per se a full comprehension of how the organisms will be influenced in their natural environment once the effluent is discharged. Moreover, the complementary avoidance response was rapid, sensitive and simple to quantify in the form of a point estimate of the effective concentration that induced $50 \%$ of responses (median avoidance effect dilution; EDil50), allowing direct comparisons between avoidance tests and other test endpoints. Such characteristics make the proposed avoidance-based test with D. magna an easily standardizable test, and, thus, suitable to be routinely implemented as a complementary tool in environmental assessments of pulp mill effluents.

Acknowledgments This research was partially funded by Fundação para a Ciência e a Tecnologia (Portugal) through postdoctoral grants to M. Moreira-Santos (reference SFRH/BPD/21721/2005) and I. Lopes (reference SFRH/BPD/22855/2005), and the project Pursuing Investigative Pathways in Environmental and Science Education (reference POCTI/CEC/34891/99).

\section{References}

Ali M, Sreekrishnan TR (2001) Aquatic toxicity from pulp and paper mill effluents: a review. Adv Environ Res 5:175-196. doi: 10.1016/S1093-0191(00)00055-1

ASTM (American Society for Testing and Materials) (2001) Standard guide for conducting Daphnia magna life-cycle toxicity tests. E 1193-97. In: Annual book of ASTM standards, vol 11.05. ASTM, Philadelphia, PA

ASTM (American Society for Testing and Materials) (2002) Standard guide for conducting acute toxicity tests on test materials with fishes, macroinvertebrates, and amphibians. E 729-96. In: 
Annual book of ASTM standards, vol 11.05. ASTM, Philadelphia, PA

Åtland $\AA$, Barlaup BT (1995) Avoidance of toxic mixing zones by Atlantic salmon (Salmo salar L.) and brown trout (Salmo trutta L.) in the limed river Audna, southern Norway. Environ Pollut 90:203-208. doi:10.1016/0269-7491(95)00002-9

CEPA (Canadian Environmental Protection Act) (1991) Priority substances list assessment report no. 2: effluents from pulp mills using bleaching. Environment Canada, Ottawa, ON

Chapman PM (2000) Whole effluent toxicity test - usefulness, level of protection and risk assessment. Environ Toxicol Chem 19:3-13. doi:10.1897/1551-5028(2000)019<0003:WETTUL > 2.3.CO;2

De Lange HJ, Sperber V, Peeters ETHM (2006) Avoidance of polycyclic aromatic hydrocarbon-contaminated sediments by the freshwater invertebrates Gammarus pulex and Aselius aquaticus. Environ Toxicol Chem 25:452-457. doi:10.1897/05-413.1

Dornfeld CB, Moreira-Santos M, Espíndola ELG, Ribeiro R (2008) Do larvae and ovipositing females of Chironomus riparius avoid copper contaminated environments? Hum Ecol Risk Assess (in press)

EC (European Commission) (1992) Classification, packaging and labelling of dangerous substances. Council Directive 92/69/EEC, OJ L 383. European Economic Community, Brussels, Belgium

EC (European Commission) (2001) Integrated pollution prevention and control (IPPC): reference document on best available techniques in the pulp and paper industry, chap. 6. European Commission, Seville, Spain

Hansen JA, Woodward DF, Little EE, DeLonay AJ, Bergman HL (1999) Behavioral avoidance: possible mechanisms for explaining abundance and distribution of trout species in a metalimpacted river. Environ Toxicol Chem 18:313-317. doi:10.1897/1551-5028(1999)018<0313:BAPMFE $>2.3 . C O ; 2$

Hewitt LM, Parrott JL, McMaster ME (2006) A decade of research on the environmental impacts of pulp and paper effluents in Canada: sources and characteristics of bioactive substances. J Toxicol Environ Health 9:341-356. doi:10.1080/15287390500195976

Hutchins FE (1979) Toxicity of pulp and paper mill effluent - a literature review. US Environmental Protection Agency Report EPA 600/3-79-013. US Environmental Protection Agency, Corvallis, OR

Kravitz MJ, Lamberson JO, Ferraro SP, Swartz RC, Boese BL, Specht DT (1999) Avoidance response of the estuarine amphipod Eohaustorius estuaries to polycyclic aromatic hydrocarbon-contaminated field-collected sediments. Environ Toxicol Chem 18:1232-1235. doi:10.1897/1551-5028(1999)018<1232:ARO TEA $>2.3 . \mathrm{CO} ; 2$

Little EE, Fairchild JF, DeLonay AJ (1993) Behavioral methods for assessing impacts of contaminants on early life stage fishes. Am Fish Soc Symp 14:67-76

Lopes I, Baird DJ, Ribeiro R (2004) Avoidance of copper contamination by field populations of Daphnia longispina. Environ Toxicol Chem 23:1702-1708. doi:10.1897/03-231
Moreira-Santos M, Donato C, Lopes I, Ribeiro R (2008) Avoidance tests with small fish: determination of the median avoidance concentration and of the lowest-observed-effect gradient. Environ Toxicol Chem 27:1576-1582. doi:10.1897/07-094.1

OECD (Organization for Economic Cooperation and Development) (1998a) Daphnia magna reproduction test. OECD guidelines for testing of chemicals, vol 211. Paris, France

OECD (Organization for Economic Cooperation and Development) (1998b) Report of the OECD workshop on statistical analysis of aquatic toxicity data. OECD series on testing and assessment, vol 10. Paris, France

OECD (Organization for Economic Cooperation and Development) (2004) Daphnia sp. acute immobilization test. OECD guideline for the testing of chemicals, vol 202. Paris, France

Parrott JL, McMaster ME, Hewitt LM (2006) A decade of research on the environmental impacts of pulp and paper mill effluents in Canada: development and application of fish bioassays. J Toxicol Environ Health 9:297-317. doi:10.1080/15287390 500195752

Riddell DJ, Culp JM, Baird DJ (2005) Behavioral responses to sublethal cadmium exposure within an experimental aquatic food web. Environ Toxicol Chem 24:431-441. doi:10.1897/ 04-026R.1

Svecevičius G (2001) Avoidance response of rainbow trout Oncorhynchus mykiss to heavy metal model mixtures: a comparison with acute toxicity tests. Bull Environ Contam Toxicol 67:680 687. doi:10.1007/s00128-001-0177-9

Scott GR, Sloman KA (2004) The effects of environmental pollutants on complex fish behaviour: integrating behavioural and physiological indicators of toxicity. Aquat Toxicol 68:369-392. doi: 10.1016/j.aquatox.2004.03.016

Wells JB, Little EE, Calfee RD (2004) Behavioral response of young rainbow trout (Oncorhynchus mykiss) to forest fire-retardant chemicals in the laboratory. Environ Toxicol Chem 23:621-625. doi:10.1897/02-635

Wentsel R, McIntosh A, McCafferty W, Atchison G, Anderson V (1977) Avoidance response of midge larvae (Chironomus tentans) to sediments containing heavy metals. Hydrobiologia 55:171-175. doi:10.1007/BF00021058

West CW, Ankley GT (1998) A laboratory assay to assess avoidance of contaminated sediments by the fresh water oligochaete Lumbriculus variegatus. Arch Environ Contam Toxicol 35:2024. doi:10.1007/s002449900343

Wiklund A-KE, Börjesson T, Wiklund SJ (2006) Avoidance response of sediment living amphipods to zinc pyrithione as a measure of sediment toxicity. Mar Pollut Bull 52:96-99. doi:10.1016/j.mar polbul.2005.08.023 